\title{
DESENVOLVIMENTO HUMANO NA CIBERCULTURA: A IMPORTÂNCIA DE PENSAR EM UM DIREITO RESILIENTE
}

\section{HUMAN DEVELOPMENT IN CYBERCULTURE: THE IMPORTANCE OF THINKING ABOUT A RESILIENT RIGHT}

Luis Gustavo Gomes Flores ${ }^{1}$

\section{RESUMO}

O presente artigo tem como tema de estudo, a importância da concepção de Resiliência do Direito para pensar o Desenvolvimento Humano em face dos desafios trazidos pelo conjunto de tendências denominados por Pierre Levy de Cibercultura. Para tanto, se buscou responder o problema de pesquisa que indaga: Quais os desafios da Sociedade Complexa e da Cibercultura para o aprimoramento do Direito e para o Desenvolvimento Humano? Trata-se de um trabalho crítico reflexivo que tem como objetivo geral, demonstrar a necessidade que se tem no Direito de pensar novas possibilidades de observação que leve em consideração a importância da inovação no Direito para enfrentar a complexidade social, fortemente marcada pela Cibercultura. Para tanto, se utilizou a método sistêmico construtivista, que pressupõe a utilização de pressupostos e categorias da Teoria dos Sistemas Sociais Autopoiéticos e do Construtivismo Radical, como forma de observação e abordagem da respectiva temática, bem como a utilização de pesquisa bibliográfica. Tem-se como resultado a possibilidade de observação de novas perspectivas a serem consideradas, a partir de um potencial ainda não explorado suficientemente, mas considerando as contribuições da Resiliência do Direito abre-se novas possibilidades para pensar o desenvolvimento humano numa perspectiva sistêmica.

Palavras-chave: Desenvolvimento Humano, Cibercultura, Resiliência do Direito.

\begin{abstract}
:
This article has as its subject of study, the importance of the concept of Law Resilience to think about Human Development in the face of the challenges brought by the set of trends named by Pierre Levy de Ciberculture. To this end, we sought to answer the research problem that asks: What are the challenges of the Complex Society and Cyberculture for the improvement of the Law and for Human Development? It is a reflexive critical work that has as its general objective, to demonstrate the need in the Law to think about new possibilities of observation that takes into account the importance of innovation in Law to
\end{abstract}

\footnotetext{
${ }^{1}$ Professor do Programa de Pós-Graduação de Mestrado em Direito da UNIJUÍ - Mestrado em Direitos Humnaos, Possui graduação em Direito pela UNISC e Mestrado, Doutorado e Pós-Doutorado pelo Programa de Pós-Graduação da UNISINOS. Professor da disciplina e do projeto de pesquisa denominados: Desenvolvimento Humano, Transformações Sociais e Resiliência do Direito. Universidade Regional do Nordeste do Estado do Rio Grande do Sul - UNIJUÍ, Rio Grande do Sul - Brasil. ORCID: https://orcid.org/0000-0002-0462-4094 Lattes: http://lattes.cnpq.br/1163837693773950 E-mail:
} gustavogf7@gmail.com 
face the social complexity, strongly marked by Cyberculture. For this, the systemic constructivist method was used, which presupposes the use of assumptions and categories of the Theory of Autopoietic Social Systems and Radical Constructivism, as a way of observing and approaching the respective theme, as well as the use of bibliographic research. As a result, the possibility of observing new perspectives to be considered, based on a potential not yet sufficiently explored, but considering the contributions of the Resilience of Law, opens up new possibilities for thinking about human development in a systemic perspective.

Keywords: Human Development, Cyberculture, Resilience of Law.

\section{INTRODUÇÃO}

Na sociedade atual as múltiplas possibilidades para o desenvolvimento humano, também são um dos seus maiores obstáculos. Isso se justifica em razão de que nesta forma de sociedade a multiplicidade de possibilidades exige uma capacidade de observação e decisão suficiente para enfrentar a complexidade social, potencializada pela expansão tecnológica e um conjunto de aspectos, efeitos e tendências que Pierre Levy chamou de Cibercultura. Por isso, considerando a importância da perspectiva jurídica, interessa compreender os desafios da sociedade complexa e da Cibercultura, tanto para o aprimoramento do Direito, como para as condições de realização do desenvolvimento humano.

Nesse sentido, para enfrentar essas questões busca-se o desenvolvimento de uma reflexão que tem como tema, a importância da concepção de Resiliência do Direito para pensar o Desenvolvimento Humano em face dos desafios trazidos pelo conjunto de tendências denominados por Pierre Levy de Cibercultura. Para tanto, busca-se responder o problema de pesquisa que indaga: Quais os desafios da Sociedade Complexa e da Cibercultura para o aprimoramento do Direito e para o Desenvolvimento Humano?

Trata-se de um trabalho crítico reflexivo que tem como objetivo geral demonstrar a necessidade que se tem no Direito de pensar novas possibilidades de observação que leve em consideração a importância da inovação no Direito para enfrentar a complexidade social, fortemente marcada pela Cibercultura.

Nesse sentido, o trabalho foi desenvolvido em três pontos: No primeiro ponto, se desenvolveu uma reflexão sobre as condições epistemológica necessárias para o Direito construir uma observação adequada ao contexto de uma sociedade complexa. 
No segundo ponto observa-se alguns aspectos das mudanças sociais desencadeadas pelo avanço das tecnologias digitais, potencializando a complexidade social e revelando o contraste entre perspectivas do sistema jurídico e a dinâmica do ambiente social que colocam em evidência as fragilidades jurídicas na realização dos Direitos Humanos, em especial no que diz respeito ao Direito ao Desenvolvimento Humano.

No terceiro ponto foi acentuada a importância de pensar a mudança, tanto na sociedade, como no Direito, e o necessário aprimoramento das reflexões e operacionalizações do mesmo. Significa dizer que o Direito precisa ser resiliente para enfrentar seus (novos e antigos) desafios e assim melhor contribuir para a garantia e realização do desenvolvimento humano reconhecido em todas as esferas do Direito.

Para tanto, se utilizou a método sistêmico construtivista, que pressupõe a utilização de pressupostos e categorias da Teoria dos Sistemas Sociais Autopoiéticos e do Construtivismo Radical, como forma de observação e abordagem da respectiva temática, através de pesquisa bibliográfica. Assim o trabalho se constitui como uma provocação reflexiva que sugere profundas mudanças na forma de observação (compreensão), organização e operacionalização do Direito, para que este seja capaz de apresentar, progressivamente, respostas cada vez mais satisfatórias para a sociedade como um todo.

\section{REQUESTIONAMENTO DA EPISTEMOLOGIA JURÍDICA: CONDIÇÕES PARA COMPREENDER O DIREITO NA SOCIEDADE COMPLEXA}

Desde a Grécia Antiga o conhecimento tem sido motivo de muitas reflexões. Pressupõe a reflexão sobre a capacidade de observação do mundo e suas múltiplas formas de representação. Trata-se de um tema chave que pode comprometer ou qualificar as leituras e entendimentos sobre a realidade.

Pode-se considerar que desde a alegoria da Caverna de Platão (1949), aos maiores avançados da Física na atualidade, é possível compreender o esforço em buscar certo aprimoramento da capacidade de observação. Como no documentário Janela da Alma, produzido por João Jardim e Walter Carvalho (2001), não se trata de pensar essa questão simplesmente como um ato de enxergar ${ }^{2}$ que se realiza objetivamente com os olhos. De

\footnotetext{
2 Trata-se de um documentário dirigido e produzido por João Jardim com codireção de Walter Carvalho cujo título é Janela da Alma e sugere uma reflexão sobre múltiplas formas de observar o mundo e por sua vez constituir uma noção de realidade através da qual cada um também se autoconstitui.
} 
acordo com a ideia que inspirou o nome deste documentário, não se observa com as janelas, mas sim através delas. Com isso a concepção de observação corresponde a uma forma de construção e compreensão da realidade ${ }^{3}$.

Um processo de observação é uma operação de reestruturação da complexidade, como uma forma de compreensão e representação simbólica da realidade observada e de certa forma construída. (MATURANA, 2000, p. 61). Isso também ocorre no sistema do Direito. A exposição de fatos em uma petição inicial, em uma contestação ou mesmo em cada interpretação, envolvem observações que significam certa construção da realidade, elaborada de uma perspectiva específica no âmbito do Direito. (LUHMANN, 2005, p. 89).

Nesse processo, se pode observar perspectivas conservadoras e não conservadoras. Em qualquer uma das perspectivas o excesso geralmente revela-se um problema. No caso do Direito, em diversos momentos será possível constatar a insuficiência de perspectivas excessivamente conservadoras. Contudo, convém considerar que a existência e manutenção de certo conservadorismo nem sempre ocorre em razão de uma incapacidade de observação do contexto social. Muitas vezes são sustentadas (até retoricamente e) propositalmente em razão de algum interesse específico (velado ou explicito), como conservação de alguma forma de controle na produção do sentido jurídico. As vezes uma postura dogmática favorece a manutenção e a justificação jurídica de certos interesses.

Ao longo da história, em diversos saberes, inclusive no Direito, heranças epistemológicas da Modernidade já deram provas de sua insuficiência para pensar a complexidade da Sociedade atual. Apesar dessa crítica já ter sido realizada de muitas perspectivas diferentes, o peso da razão moderna ainda exerce grande influência na cultura jurídica ocidental.

A matriz jurídica dominante na Modernidade foi o normativismo jurídico (ROCHA, 2003, p. 185). Adequado à sua época, dando respostas para as demandas de um determinando momento histórico, emergiu como uma grande contribuição para um desenvolvimento do Direito. Contudo, a sociedade passou a se tornar mais complexa, assumindo contornos dinâmicas diferentes de quando o normativismo jurídico foi forjado.

\footnotetext{
${ }^{3}$ É claro que a própria concepção de realidade é altamente complexa. Falamos de forma genérica, utilizando uma linguagem comum, em realidade do nosso dia-a-dia, do que já aconteceu, de um processo geofísico do qual fazemos parte, do que é possível criar. De alguma forma elaboramos uma condição de sentido que nos permite uma compreensão contingente da realidade que podemos observar e representar simbolicamente. Contudo, por exemplo, estudos desenvolvidos pela Física quântica, revelam um mundo de infinitas possibilidades, onde a realidade é uma construção interna, produzida através de uma rede complexa de significações, fruto da capacidade de observação.
} 
Uma cultura jurídica forjada em longa prática de um Direito Corrente ${ }^{4}$ que privilegiou o aspecto da operacionalização (FERRAZ JR, 2011, p. 18), contribuiu muito para a consolidação de uma epistemologia Moderna no âmbito jurídico. Isso resultou em grande simplificação através de aspectos técnicos, e de "complexificações" fabricadas burocraticamente na produção de conhecimentos jurídicos fragmentados, reducionistas e compartimentalizados. Essa forma de pensar o Direito é reconhecida como Dogmática Jurídica (ROCHA, 2003, p. 195). Acentua a operacionalização do Direito que, por um lado é importante, mas por outro, pode se tornar um problema quando implementada de forma excessivamente conservadora.

Nessa perspectiva a observação jurídica é empobrecida por uma ocultação dos aspectos multidimensionais do mundo e a incapacidade de perceber essa própria ocultação. Poderia se mencionar a existência de uma espécie de ponto cego (FOERSTER, 1996, p. 5974) na observação jurídica. Um obstáculo interno (BACHELARD, 2011 p. 15-16) para acessar a complexidade que se revela como uma crise epistemológica no Direito.

Assim, não é difícil constatar que o Direito carece de uma revisão epistemológica que possibilite desenvolver reflexões capazes de enfrentar a complexidade social, não apenas como uma necessidade, mas também como uma oportunidade para desenvolver a evolução do Direito (LUHMANN, 2005, p. 331). Por isso é tão relevante repensar as condições necessárias para o aprimoramento da epistemologia jurídica.

Uma estratégia que se pode utilizar para identificar as insuficiências jurídicas é a observação de certos contrastes entre a dinâmica das demandas sociais e a dinâmica de operacionalização do Direito. (ROCHA, 2003, p. 197).

O contexto social contemporâneo constitui o que chamamos aqui (didaticamente) de complexidade real ${ }^{5}$ (extremamente dinâmica e contingente). Contudo, as leituras que se pode fazer dessa complexidade real, a partir do Direito, são leituras parciais e correspondem, a uma "realidade parcial - construída pelo Direito"6. Essa complexidade social é reestruturada

\footnotetext{
${ }^{4}$ Direito Corrente é considerado um Direito que se operacionaliza predominantemente a partir da programação condicional, mas pressupõe uma postura de abertura para o próprio aprimoramento. É utilizado para diferenciar uma prática jurídica corrente, onde a dogmática busca garantir a operacionalização do Direito mantendo certa disposição de aprimoramento de uma pratica jurídica que acentua excessivamente uma perspectiva mais conservadora e por isso é chamada pejorativamente de dogmática jurídica

${ }^{5}$ Para fins didáticos se busca compreender com essa expressão indicar a diferença entre o que se consegue observar da complexidade, constituindo uma perspectiva de realidade, e o que independente da incapacidade de um observador conseguir observar existe numa dimensão da complexidade mais ampla, que se convencionou chamar aqui de real.

${ }^{6}$ Significa que a construção da "realidade", de certa forma, é uma construção parcial, específica e seletiva de uma dimensão mais ampla que pode ser indicada aqui como "o real".
} 
a partir da perspectiva e do sentido jurídico. Não é aleatório que numa perspectiva sistêmica do Direito e da sociedade aquele pode ser compreendido como um sistema parcial desta.

Dessa forma, a concepção de realidade observada/construída a partir da perspectiva do Direito, dependerá proporcionalmente da respectiva capacidade de observação e consequentemente das suas próprias estruturas internas que poderão permitir a ele desenvolver uma observação ampla e aberta, ou restrita e reducionista.

Aqui a epistemologia terá grande importância no que diz respeito aos rumos que a operacionalização do Direito pode tomar. Interessa pensar uma epistemologia que permita que a realidade construída pelo Direito seja o mais compatível e coerente possível com a complexidade (real) da Sociedade. Isso significa ser capaz de considerar riscos, paradoxos e contingências (CLAM, 2006, p. 73-74) como aspectos do contexto que precisam ser considerados nas reflexões jurídicas.

Se a "realidade" depende da maneira como se observa a Sociedade, a própria compreensão dos problemas ou demandas que dela emergem também são dependentes de uma construção (de certa observação), que em alguma medida é específica (MATURANA; VARELA, 2001). Logo, uma observação/construção da realidade equivocada ou insuficiente, poderá comprometer a qualidade e a eficácia das respostas que, a partir do Direito, serão elaboradas para as demandas sociais ${ }^{7}$.

Para escapar dessa problemática é importante compreender alguns aspectos necessárias para se buscar certo aprimoramento da capacidade de observação do Direito. Algumas das principais condições para o aprimoramento da observação, enquanto forma de sofisticação da epistemologia jurídica, podem ser consideradas como sendo: 1) a compreensão de pertencimento à uma conjuntura complexa e interdependente, 2) flexibilidade, 3) disposição para considerar múltiplos saberes, 4) capacidade de conservação e mudança, 5) disposição de questionar permanentemente os pressupostos jurídicos, e a 6) capacidade de enfrentar encadeamentos diversos e complexos de significações sociais, buscando explorar ao máximo as novas possibilidades. ${ }^{8}$

\footnotetext{
${ }^{7}$ Uma observação reducionista, simplista ou excessivamente conservadora, poderá, da mesma forma, resultar em respostas jurídicas reducionista, simplista ou excessivamente conservadora. Considerando que a Sociedade é constituída de diferentes sistemas sociais parciais, apresentar uma resposta para "a sociedade" significa apresentar uma resposta que esteja, de alguma forma, voltada para múltiplas perspectivas de saberes, representadas também na foram de sistemas sociais.

8 Tudo isso pode ser facilmente compreendido através da ideia de autopoiése. (MATURANA; VARELA, 1997).
} 
1) Quanto à compreensão de pertencimento à uma conjuntura complexa e interdependente, consiste no entendimento de que o Direito constitui uma das estruturas sociais e está imerso em um ambiente compreendido por diversos âmbitos de conhecimentos, chamados também de sistemas sociais, cada qual com sua função e forma específica de se auto-organizar (LUHMANN, 2016, p. 29-30). ${ }^{9}$

2) Quando à flexibilidade, esta pode ser importante para tensionar os aspectos conservadores do Direito que, pelo fato de se mostrarem insuficientes diante do contexto social complexo, contrastam com aspectos mais desenvolvidos de outras áreas ou não alcançam efetivamente a satisfação das demandas sociais. A flexibilidade pode ser importante para um primeiro movimento de superação de aspectos dogmáticos, mas depende de certa reflexividade para que não seja utilizada como um recurso para a manipulações do Direito (FLORES; ROCHA, 2016, p. 55) e eventuais mudanças resultarem em retrocessos.

3) Sobre a disposição para considerar múltiplos saberes, torna-se importante na medida em que permite observar como são elaboradas as concepções (de mundo) na perspectiva da dogmática jurídica em comparação com outras áreas de conhecimento que podem dar relevantes contribuições (e demandas) para as reflexões jurídicas. (NICOLESCU, 2005, p. 52-53).

4) Quanto à capacidade de conservação e mudança, diz respeito à importância de saber observar de forma não-dogmática que a "conservação" possui um papel importante para garantir a manutenção das aquisições evolutivas. Isso pode ser observado principalmente no que diz respeito aos Direitos Humanos e Fundamentais, enquanto conquistas sociais e que ao mesmo tempo, para se manter em um mundo dinâmico é preciso serem equacionados à ideias de "mudança". (ROCHA, 2003, p. 199). É a mudança que terá condições de possibilitar a atualização, o aprendizado e a evolução do Direito. Contudo, não se trata de considerar a mudança simplesmente porque se está imerso numa sociedade em constante movimento, mas considerar a importância de produzir mudanças evolutivas, considerando um processo reflexivo de seleção do que deve ser mudado e o que deve ser preservado. (OST, 1999, p. 195). A conservação permite garantir avanços já realizados e a mudança possibilita o aprendizado necessário para superar obstáculos e possibilitar uma realização evolutiva do Direito.

\footnotetext{
${ }^{9}$ Essa perspectiva já sugere que o referencial teórico para a presente reflexão possui uma grande contribuição da perspectiva da Teoria dos Sistemas Sociais (Autopoiéticos) de Niklas Luhmann.
} 
5) A disposição de questionar permanentemente os pressupostos jurídicos, indica uma reflexão sobre observação de aspectos a serem aprimorados, bem como, mecanismos eficientes para compreender e diagnosticar a sociedade em suas demandas. Isso permite pensar em um processo de monitoramento constante da evolução jurídica, considerando a sua atuação diante desse contexto. (LUHMANN, 2005, p. 304).

6) Nessa perspectiva, a capacidade de enfrentar encadeamentos complexos de significações e buscar explorar novas possibilidades, diz respeito à necessidade de repensar o Direito considerando a importância das possibilidades de contribuição de certa perspectiva transdisciplinar. (NICOLESCU, 2005, p. 54-55). Na medida em que o Direito possui a função de elaborar respostas aos problemas de uma sociedade complexa, constituída por inúmeros sistemas sociais, ele precisa considerar a multiplicidade de perspectivas possíveis.

Essas sãos as condições necessárias de aprimoramento epistemológico que possibilitam o desenvolvimento da observação jurídica e consequentemente da sua operacionalização. Isso é cada vez mais necessário e urgente para enfrentar a complexidade da sociedade contemporânea, incrementada pela Cibercultura.

Os constantes avanços tecnológicos que potencializam a complexidade social desencadeiam inúmeras transformações que são marcadas pela grande velocidade de acontecimentos, que também são recheados de imprevisibilidades, incertezas e riscos. Tudo isso tende a dificultar qualquer operacionalização do Direito que siga uma orientação excessivamente dogmática.

Isso pressupõe, não somente a concepção do Direito como um sistema dinâmico e evolutivo, mas também que ele está imerso em um ambiente igualmente dinâmico e complexo, o que exige uma constante reflexão envolvendo a articulação interdependente, permanente e indissociável entre sistema e ambiente. (LUHMANN, 2016, p. 38).

A importância de pensar uma renovação da epistemologia jurídica experimentando certa abertura para a transdisciplinaridade implica em repensar também a cultura jurídica de forma crítica. Isso exige uma profunda avaliação das posturas tradicionalmente conservadas no Direito que dificultam a realização dos Direitos Humanos, em especial do Direito ao Desenvolvimento Humano, ou mesmo contribuem para recorrentes violações desses direitos que se cristalizam de forma imperceptíveis no cotidiano, através da naturalização de pequenas (mas significativas) castrações das relações humanas. 
Por isso, os Direitos Humanos, precisam ser revisitados de forma crítica ${ }^{10}$, por uma epistemologia jurídica sofisticada, a fim de serem considerados numa perspectiva complexa, sobretudo, a partir das implicações causadas pelas tendências emergentes de uma Cibercultura e suas implicações no Desenvolvimento Humano.

\section{CIBERCULTURA COMO UM DESAFIO AO DESENVOLVIMENTO HUMANO}

Vive-se uma época em que novas situações surgem a todo momento e demandam novas reflexões. Demandas ainda não solucionadas, deverão ser observadas a partir de olhares diferenciados a fim de explorar alternativas ainda não experimentadas.

Grande parte das transformações sociais são desencadeada por um "conjunto de técnicas (materiais e intelectuais) de práticas, de atitudes, de modos de pensamento e de valores" denominada por Pierre Levy (2007, p. 17) de Cibercultura. Uma cultura que se constitui a partir das novas formas e configurações de relações sociais que passam a ocorrer através de recursos tecnológicos no âmbito do ciberespaço. (LEVY, 2007, p. 17. Isso se tornou possível com uma ampla e veloz expansão das tecnologias digitais de informação e comunicação. Avanços no âmbito da informática que possibilitou a produção de uma comunicação digital, através da web, com a conexão de redes de computadores em âmbito global a partir do espaço virtual da Internet. (LEVY, 2007, 43-44).

Essa expansão tecnológica se estendeu por praticamente todo o âmbito social reconfigurando relações, comportamentos e a vida social nos mais variados aspectos. Transcendendo fronteiras tradicionais do espaço-tempo através da utilização das mais variadas tecnologias, se mostra presente na vida social desde o uso de um smart fone, que podem ser carregado no bolso por bilhões de usuários, até os mais sofisticados laboratórios, estudos e equipamentos de ponta, com a utilização da Big Data e Inteligência Artificial. (BARONE; BOESING; 2015).

Apesar dessa ampla expansão, as tecnologias digitais, em si, não podem ser consideradas ruins ou boas. Existe uma diversidade de consequências, tanto benéficas, como nocivas para o desenvolvimento humano em sociedade. Contudo, paradoxalmente isso pode

\footnotetext{
${ }^{10}$ Embora se reconheça a relevante contribuição da contribuição de Joaquím Herrera Flores (2009) com sua teoria crítica dos direitos humanos, aqui se pretende uma perspectiva crítica que seja mais transdisciplinar e consiga trazer para o debate pressupostos e perspectivas teóricas já bem desenvolvidas em outros âmbitos do saber que não conseguiram maior ressonância no universo jurídico em razão de certa Armadura Dogmática do Direito. (FLORES, 2018, p. 129).
} 
ser determinado pelo próprio ser humano, que se mostra um elemento altamente contingencial, tornando a utilização das tecnologias um aspecto de alta indeterminação quanto à utilização e possíveis consequências na dinâmica de organização da sociedade.

A Cibercultura estabelece um conjunto de tendência na dinâmica das relações sociais com uma diversidade de consequências, tanto benéficas, como nocivas para $\mathrm{o}$ desenvolvimento humano. Se constitui como um espaço fértil para potenciais emancipatórios e anti-emancipatórios, entre eles, inúmeras violações aos Direitos Humanos. (LEVY, 2007).

O desenvolvimento humano é compreendido aqui a partir da perspectiva estabelecida pelo Programa das Nações Unidas para o Desenvolvimento (PNUD), no início da década de 1990, como resposta a uma expansão econômica mundial que não correspondia a melhores condições de vida para grande parcela de população em diversas partes do mundo. (MARIANO, 2019, p. XX).

Contou com as contribuições dos economistas Amartya Sen e Mahbub ul Haq, que desenvolveram o Índice de Desenvolvimento Humano - IDH (MARIANO, 2019, p. 173), utilizado anualmente pelo PNUD (através de seus relatórios) para identificar o nível de desenvolvimento humano nos países membros da Organização das Nações Unidas (ONU) basicamente a partir de três indicadores: expectativa de vida, educação e renda per capta. (PNUD, s/d). Além do IDH foram sendo criados outros importantes indicadores, o que já sugere a complexidade no âmbito do tema do desenvolvimento humano. (MARIANO, 2019, p. XXI).

Paradoxalmente o direito ao desenvolvimento humano não pode ser concedido (simplesmente "dado") pelo estado. É um conjunto complexo de condições fundamentais para o pleno desenvolvimento humano, que deve permitir como consequência a realização de uma vida digna. São essas condições que precisam ser construídas socialmente e disponibilizadas a todos.

Para compreender o que significa o desenvolvimento humano é preciso olhar para as capacidades humanas e as oportunidades disponíveis (em termos de condições e direitos básicos), considerando a liberdade do humano de poder definir que tipo de vida deseja levar, independente das singularidades de cada um. (PNUD, 2019).

A proposta de consideração do Desenvolvimento Humano, indica a intencionalidade de uma mudança de paradigma, a partir de uma perspectiva que acentua a importância do desenvolvimento humano, em contraponto ao desenvolvimento exclusivamente econômico. 
Acentua a importância do ser humano e da realização dos seus potenciais através de oportunidades e liberdade para tanto.

Assim a concepção de desenvolvimento humano compreende aspectos da vida social que os indicadores econômicos tradicionais não são capazes de mensurar, como qualidade de vida, bem estar e a felicidade, consideradas de forma convergente tanto no plano individual como coletivo. (MARIANO, 2019, p. 174-175).

A preocupação com o desenvolvimento humano surge para reforçar direitos que já são consagrados formalmente inclusive como Direitos Humanos e fundamentais, mas que são muitas vezes desprezados a partir de perspectivas unilaterais de desenvolvimento, em especial o "desenvolvimento econômico". Nesse sentido, a concepção de desenvolvimento humano é ampla, considerando inclusive a importância de um desenvolvimento econômico, de forma sustentável, equitativo e não predatório. Pressupõe um desenvolvimento conjuntural, onde, por exemplo, uma renda adequada pode possibilitar a aquisição de bens que são fundamentais para satisfazer as necessidades para uma vida digna convergente com a realização de outros direitos. (MARIANO, 2019, p. XIX-XX).

Num primeiro momento o desenvolvimento humano é um parâmetro importante para se pensar em indicadores que permitem observar melhor o desenvolvimento social. Contudo, as capacidades humanas são tão diversificadas e complexas que esse entendimento deve ser pensado, para além dos indicadores, em uma perspectiva filosófica, antropológica, sociológica, psicológica e etc. Isso permite recordar a tradição grega que considerava o conhecimento uma virtude e valorizava o desenvolvimento das potencialidades humanas como a finalidade dos seres humanos na realização de uma vida boa. Assim o desenvolvimento humano deve ser pleno, conjuntural, considerando a complexidade social e as oportunidades e riscos da cibercultura, a fim de possibilitar construção coletiva das condições fundamentais para se alcançar uma cidadania emancipada.

As mudanças sociais desencadeadas pela expansão das tecnologias digitais e eventuais repercussões em relação aos Direitos Humano, são grandes desafios para a realização plena do Desenvolvimento Humano. Assim, uma proposta voltada para garantir as condições para a realização do Desenvolvimento Humano sugere uma necessidade de diversos aspectos que precisam ser compreendidos de forma conjunta e sistêmica, o que pressupõe uma epistemologia jurídica mais adequada a compreensão dessa questão no âmbito da Cibercultura. (MARIANO, 2019, p. XX). 
Os Direitos Humanos como conhecemos hoje são heranças da Modernidade, onde segundo a perspectiva luhmanniana, emerge uma forma de Sociedade funcionalmente diferenciada e por isso altamente complexa. Para dar conta dessa complexidade a Sociedade foi compreendida como um sistema social que se auto-organiza a partir das comunicações que produz. Por isso para Luhmann a Sociedade é comunicação. (LUHMANN, 2007, p. 18).

Tudo que ocorre enquanto expressão social se dá através da comunicação, um elemento fundamental para a realização da sociedade. Através dela que as relações e decisões ocorrem conectando a coletividade. Tudo o que acontece dizendo respeito ao social acontece mediante a comunicação. ${ }^{11}$ Por isso, a sociedade é tão afetada pelas tecnologias digitais e pela Cibercultura que amplificam extraordinariamente o alcance das comunicações. Elas transformam drasticamente as inúmeras relações comunicativas desencadeando as seguintes mudanças:

a) Potencializaram o alcance das ressonâncias comunicativas no espaço-tempo para além de dimensões individuais. Dessa forma, se abre a possibilidade para a vivencia de estar simultaneamente próximo e distante, sozinho e acompanhado.

Aparelhos tecnológicos passaram a substituir amplamente a presença pessoal física, tanto nas relações de trabalho como nas relações particulares. Isto pressupõe simultaneamente riscos e benefícios. Pode significar um potencial para desenvolver lucidez e conhecimento, como também para a distração e alienação. Possibilita tanto o desenvolvimento da autonomia, coletivismo e cooperação, como também da dependência, individualismo e concorrência.

b) Tornaram as comunicações instantâneas, ocorrendo em tempo real, o que em um amplo espaço virtualizado, possibilitou o desenvolvimento de uma dinâmica social extremamente veloz.

c) Desmaterializou as comunicações, fazendo com que os documentos não tenham mais a necessidade de uma estrutura física, mas simplesmente uma estrutura virtual.

d) Desterritorializou as comunicações no sentido de possuir um alcance para além do território estatal, das fronteiras geográficas, físicas ou materiais, ocorrendo em um espaço extremamente amplo, constituído em uma rede mundial de computadores.

e) Possibilitou amplo acesso à informações e conhecimentos permitindo maior circulação de perspectivas diferentes de informações, bem como, uma grande ambivalência

\footnotetext{
${ }^{11} \mathrm{O}$ que não é comunicação (social) diz respeito à dimensão biológica (física) ou à dimensão psíquica. É a comunicação um elemento de conectividade social por excelência.
} 
entre transparência e ocultação, entre garantia ou violação da privacidade, na disponibilização de dados tanto públicos como privados.

f) Tornou mais evidente a complexidade das informações, tanto em termos de transparência como de ocultação, na medida em que as informações deixaram de ser monopólio de redes de rádio e televisão, podendo ser compartilhadas informações contraditórias por qualquer pessoa ou, da mesma forma, serem hackeadas. Contudo, isso também pode gerar diversos problemas de fontes desqualificadas, bem como o reconhecimento de fontes qualificadas.

Essa revolução nas comunicações ampliou extremamente a capacidade e o alcance das relações sociais no espaço-tempo inaugurando um novo campo de conexões globais, o Ciberespaço, compreendido como um "novo meio de comunicação que surge da interconexão mundial dos computadores" (LEVY, 2007, p. 17). Trata-se de um ambiente virtual que conecta as infraestruturas materiais de comunicações digitais, um universo de informações e os seres humanos que o alimentam e se relacionam virtualmente. Em razão dessas conexões de redes virtuais com amplitude global, Manuel Castells passa a chamar essa forma de organização social de Sociedade da informação ou Sociedade em rede (CASTELLS, 2005).

Há um excesso de informações disponibilizadas na Internet. Muitas delas são distorcidas, descontextualizadas ou falsas, a exemplo das fake News ${ }^{12}$. A incerteza e desconfiança que se cria com isso gera uma enorme dificuldade para os processos de escolha e tomada de decisões. A necessidade de garantir certa capacidade de seleção e gerenciamento de informações, coloca em evidência a importância de desenvolver certa forma de confiança (LUHMANN, 1996) como redução da complexidade. Isso permite a viabilização de relações, processos e instituições com maior confiabilidade quanto a capacidade e legitimidade de responder às demandas sociais, em especial às que significam condições fundamentais para o desenvolvimento humano. (MARIANO, 2019, p. 35).

Além disso, convém mencionar que existem inúmeros déficit de direitos sociais que impactam na realização do desenvolvimento humano, seja como violação ou mesmo com a inviabilização dos Direitos Humanos. Isso pode inclusive já existir a mais tempo do que se possa imaginar, de forma silenciosa e invisível. A eventual identificação desse problema

\footnotetext{
${ }^{12}$ São informações produzidas notícias falsas, matérias publicadas por blogs e sites falsos, ou mesmo sistemas de computador que não só elaboram notícias falsas mas também disparam para uma grande quantidade de usuários de acordo com as preferências já captadas também através de programas muitas fezes fornecidas pelos próprios usuários através de programas específicos para a obtenção desses dados.
} 
pode ocorrer, não porque a ocorrência seja momentânea, mas porque talvez agora essa ocorrência esteja sendo veiculada nas comunicações sociais. (CORSI; BARALDI; ESPÓSITO, 1996, p. 210). Isso pode gerar uma sensação de que possa estar havendo na atualidade um aumento de violação dos Direitos Humanos, quando na realidade o que está ocorrendo é somente a comunicação de algo que já existia.

Não estar na comunicação da sociedade, pode gerar a sensação de não existência. Em se tratando de desenvolvimento humano, isso pode sugerir uma violenta forma de exclusão social. A própria leitura da concepção de desenvolvimento humano no contexto da sociedade complexa exige novos aprimoramentos para se chegar a uma forma consistente de se mensurar os níveis de desenvolvimento humano. Nesse contexto, as novas tecnologias e o acesso à informação e possibilidades de comunicação na perspectiva aberta pela Cibercultura, precisam ser elementos de grande relevância para compreender o desenvolvimento humano, tanto em seus aspectos nocivos como em seus benefícios e potencialidades para a emancipação humana.

A Cibercultura produze um grande paradoxo de inclusão e exclusão. A revolução desencadeada nas comunicações vem ocorrendo de uma forma tão ampla que engloba a todos, quase inevitavelmente. Isto exige que aqueles que estejam à margem dessas comunicações digitais tenham que se esforçar para se adaptar, sob pena de serem excluídos. Convém ter especial atenção a uma forma perversa de exclusão social que é a exclusão da comunicação. Essa exclusão pode alcançar efeitos dramáticos. Significa que para algo ou alguém ser observado na sociedade é preciso participar ou ser tematizado na comunicação social. Não basta que algo ocorra de fato, também é preciso que seja parte da realidade construída como observação e comunicação social. (LUHMANN, 2007, p. 23).

Essa exclusão tende a ter fortes implicações para o Desenvolvimento Humano, uma vez que um dos fatores fundamentais são as condições de educação. Um âmbito que recebe forte influência das novas tecnologias digitais de informação e comunicação. As tecnologias têm revolucionado a educação através não apenas da sua modalidade à distância (EAD), mas também pela possibilidade de acesso a uma ampla quantidade de materiais disponível no ciberespaço. Isso tem um potencial de emancipação extremamente relevante na atualidade. Contudo, é preciso ter acesso às estruturas necessárias para usufruir das conexões no ciberespaço, juntamente com um processo educativo voltado à gestão e otimização dos conteúdos obtidos na Internet. (PISCHETOLA, 2016, p. 13-14). 
O processo educativo em geral já compreende certa alfabetização no uso e aproveitamento das tecnologias digitais de forma inevitável. Contudo, a falta de acesso a estes recursos pode gerar uma exclusão das comunicações (CORSI; BARALDI; ESPÓSITO, 1996, p. 123), que por sua vez, significa uma exclusão de muitas relações sociais que são estabelecidas através de conexões on-line. Uma exclusão dos processos educativos (PISCHETOLA, 2016, p. 21), desencadeará uma cadeia de outras exclusões sistêmicas, como a exclusão do trabalho formal, que por sua vez pode gerar a exclusão do sistema econômico, uma vez que sem a comprovação de renda, pode haver diversas exclusões que serão obstáculos à obtenção de créditos. Isso poderá gerar impacto tanto no que diz respeito à condições fundamentais de consumo de alimentos, moradia e medicamentos, que por sua vez pode gerar implicações no âmbito da saúde. (LUHMANN, 2007).

Além disso, uma pessoa em condição de analfabetismo ou mesmo de uma formação baseada apenas em aspectos técnicos de um conhecimento, baseado em uma razão instrumental, pode ter diversas dificuldades em selecionar e compreender de forma crítica as informações disponíveis, podendo consumir predominantemente conteúdos não educativos e inclusive conteúdos que produzem certa "desinformação". Agora a falta de senso crítico que já existia em contextos sem internet, passa a ser potencializada, tornando os indivíduos extremamente vulneráveis à informações falsas, distorcidas e à todo tipo de manipulação ideológica. Conforme a capacidade de agir de forma autônoma ou heterônoma, os efeitos nas condições e na realização do desenvolvimento humano podem ser diametralmente opostos, podendo haver condições favoráveis tanto para a alienação e manipulação ideológica, como para o esclarecimento, aprendizado e emancipação. Nesse contexto, a simples falta de acesso às possibilidades de obter informações e participar das comunicações desenvolvidas no âmbito do ciberespaço pode significar um processo de exclusão que condena os indivíduos à invisibilidade e com isso as mais variadas formas de exclusão e discriminação social.

O desenvolvimento humano envolve essa complexidade de aspectos que são interligados e precisam ser realizados conjuntamente, considerando desde as condições para educação, moradia, saúde, trabalho, cultura, lazer e o quanto isso pode contribuir para a realização do ser humano em sua plenitude a fim de gozar de um desenvolvimento humano digno de felicidade. (MARIANO, 2019, p. 201).

Por isso, pode-se compreender que uma Cultura jurídica dogmática muitas vezes contribui para a manutenção de certa invisibilidade dos problemas sociais não resolvidos 
pelo Direito. Além do Direito, em algumas situações, não ser capaz de resolver problemas antigos, complexos e sistêmicos a partir de uma única decisão jurídica, sua ineficácia, morosidade e dogmatismo pode também ter uma razão epistemológica. A insuficiência epistemológica da dogmática jurídica para pensar o contexto complexo, de certa forma, pode contribuir muito para a manutenção crônica de certos problemas sociais que se arrastam no tempo.

É praticamente evidente que tradicionalmente o Direito se operacionaliza a partir de certo conservadorismo. Busca conservar padrões de comportamento válidos no tempo para que todos possam saber como devem se comportar num futuro próximo. Num primeiro momento isso não significa necessariamente um problema e até pode ser necessário. Contudo, ocorrendo de forma excessiva pode significar um obstáculo à efetividade do Direito, em especial dos Direitos Humanos. Essa perspectiva dogmática revela fortes influência e traços de uma epistemologia jurídica forjada na Modernidade, a partir de uma concepção de mundo estável, presente na Física de Isaac Newton, mantida na filosofia de Immanuel Kant e posteriormente influenciando o normativismo de Hans Kelsen, principal referência do pensamento jurídico moderno (ROCHA, 2003-a, p. 311).

Para compreender isso é preciso considerar que o Direito possui uma lógica de operacionalização própria (auto-organizativa). Isso pode ser observado a partir de suas duas formas de operacionalização: Programação Condicional e Programação Finalística (LUHMANN, 1985, p. 29).

Como bem menciona Rocha, o Direito a partir da programação condicional tende a acentuar o passado com o intuito de controlar o futuro (ROCHA, 2003, p. 196). Nisso consiste a pretensão de que um determinado "passado selecionado", se repita nas tomadas de decisões futuras. Trata-se de uma estratégia de conservação das formas de comportamentos e valores que se pretende conservar no tempo e no espaço através de normas contrafaticas, ou seja, normas que são mantidas válidas mesmo contra eventual violação, a fim de acentuar a importância da estabilização e manutenção do Direito com longa duração. (LUHMANN, 1983, p. 45).

A auto-organização precisa de um mínimo de conservação e também de certa mudança para que seja possível a necessária atualização em relação às transformações sociais. O problema surge quando a produção de repetição, que significa conservar o passado, é excessivamente acentuada, revelando epistemologicamente suas fragilidades, defasagens e insuficiências diante de um contexto altamente complexo e dinâmico. 
A partir dessa perspectiva mais conservadora, frequentemente a complexidade social é negada por observações simplistas, reducionistas e fragmentadas que forjam uma dogmática jurídica excessivamente fechada para as influências do ambiente social. Um exemplo disso pode ser a concepção temporal do Direito em face dos avanços obtidos em outras áreas. Embora no âmbito da Física, Einstein já tenha superado a perspectiva de tempo newtoniana, no Direito essa concepção temporal que foi mantida na filosofia kantiana, também influenciou Kelsen que ainda na atualidade possui um grande peso na epistemologia jurídica. O que se pode observar é que concepções bem desenvolvidas em outras áreas parecem esbarrar numa espécie de Armadura Dogmática do Direito (ROCHA; FLORES, 2016, p. 203), que impede qualquer novo conhecimento de entrar no âmbito jurídico, a fim de evitar qualquer abalo à estabilidade conservadora dessa forma de dogmática. Assim, conhecimentos desenvolvidos em outras áreas que poderiam dar alguma contribuição para a racionalidade jurídica, sofrem forte resistência do próprio Direito quando concebido em uma perspectiva dogmática.

Se a dimensão dogmática do Direito for pensada a partir da programação condicional (LUHMANN, 1985, p. 27-28) é de se considerar que esta perspectiva se mostra relevante na sua auto-organização (LUHMANN, 2016, p. 40), pois possibilita que o Direito tenha certa operacionalização. Contudo, quando se acentua excessivamente essa perspectiva, se passa a incorrer em um ariscado conservadorismo, que pode comprometer a qualidade do Direito em face do contraste com a contextualização social, sobretudo no que diz respeito à sua eficácia na realização de direitos que constituem o Direito ao desenvolvimento humano.

Nesse sentido, pode-se observar, em contraste com a dinâmica da sociedade complexa, sinais de defasagem epistemológicas do Direito. Por isso é preciso uma epistemologia jurídica que permite saber quando o Direito precisa acentuar a estabilidade e quando deve promover a mudança. (ROCHA, 2003, p. 199).

Permitir a predominância de um excessivo conservadorismo pode resultar em certa ineficácia do Direito, que por sua vez também pode ser uma forma de violência contra os Direitos Humanos, já que pode inviabilizar as condições para o necessária e imprescindível desenvolvimento humano, fundamental condição para a realização dos demais direitos.

A ineficácia de um direito corrente pode significar, direta ou indiretamente a ineficácia do direito ao desenvolvimento humano. Por isso que os Direitos Humanos, principalmente através do direito ao desenvolvimento humano, devem estar implicados direta e epistemologicamente nas expressões mais elementares do direito corrente. É preciso 
acentuar a importância da realização dos Direitos Humanos nos níveis mais básicos e elementares do desenvolvimento humano, evitando retrocesso ao que já se conseguiu garantir (formalmente) na ordem jurídica, como um percurso já percorrido em direção da sua realização material na sociedade.

Assim a Cibercultura abre um espaço para uma importante reflexão ao problematizar epistemologias conservadoras que não são mais suficientes para pensar questões complexas, como também para amplificar as formas de relações sociais, permitindo visibilidade a inúmeras potencialidades das tecnologias, mas também diversos aspectos excludentes que obstaculizam as condições necessárias ao desenvolvimento humano.

Todo desafio ou dificuldade pode também ser uma oportunidade. Interessa aqui, sinalizar uma importante oportunidade de aprimoramento do Direito. A atmosfera de expansão tecnológica das tecnologias digitais na Cibercultura permite a necessária abertura e confronto com o novo. Assim, novas situações irão exigir certa inovação do Direito, pois eventualmente os problemas sendo inéditos, podem escapar da lógica de operacionalização dogmática de buscar no passado subsídios para responder aos problemas presentes e futuros.

Inúmeros crimes praticados através das redes de computadores (seja no âmbito da Web como da Deep Web) são apenas um exemplo, além da exclusão das comunicações, de certo aspecto da complexidade social que desafia a epistemologia jurídica, com um volume surpreendente, com alcance inimaginável e um alto nível de incerteza reconfigurando novas práticas que também podem produzir em todos os dias, alguma violação aos Direitos Humanos.

A Cibercultura evidencia a necessidade de compreender a complexidade do contexto social como uma potencialidade ambivalente que pode contribuir tanto para a emancipação, como para a alienação. Isso deve ser observado nas condições fundamentais para o desenvolvimento humano que tendem a ocorrer constantemente na dinâmica social. Devese observar se os efeitos da Cibercultura estão sendo favoráveis ou não ao desenvolvimento humano. Apesar de toda legislação internacional já desenvolva em prol dos Direitos Humanos, estes devem ser observados nas condições básicas ao desenvolvimento humano, na dinâmica da rotina social que já não pode ser pensada sem as implicações da Cibercultura.

São nas relações que cada vez mais ocorrem no âmbito do ciberespaço que se deve garantir as condições ao desenvolvimento humano e consequentemente a realização dos Direitos Humanos em geral. Na ocorrência do direito corrente, muitas vezes observados na 
ótica de ramos internos do Direito é que o Direito ao Desenvolvimento Humano e a identificação da convergência e equivalência com os Direitos Humanos deve ser reafirmada.

Historicamente as conquistas de formalização dos Direitos Humanos em tratados, declarações ou legislações estatais, apesar de serem de grande importância, não são suficientes se consideradas apenas do ponto de vista formal. São apenas o primeiro passo em direção da realização desses direitos. Talvez o segundo passo que é a busca pela realização pragmática desses direitos possa ser dado a partir da observância de certa equivalência dos direitos internos com os Direitos Humanos, sendo colocados em destaque, juntamente com um requestionamento (OST, 1999, p. 195) epistemológico do Direito. Isso pode ser desenvolvido como parte dos esforços em desenvolver a Resiliência do Direito enquanto condição de possibilidade para o enfrentamento dos novos desafios da Cibercultura e da Sociedade Complexa.

\section{RESILIÊNCIA DO DIREITO E AS CONTRIBUIÇÕES AO DESENVOLVIMENTO HUMANO EM FACE DA CIBERCULTURA}

As violações de Direitos Humanos, que muitas vezes afetam justamente as condições fundamentais para a realização do desenvolvimento humano constituem parte dos problemas que emergem da complexidade social contemporânea. Apesar de inúmeros avanços formais em termos de debates, tratados e legislações construídas para promover a realização dos Direitos Humanos, ainda persistem antigos problemas (IELBO; KETSCHAMNN, 2003, p. 118-119), bem como, problemas antigos reconfigurados a partir da Cibercultura e novos problemas a partir situações até então inéditas que emergem de uma sociedade em constante transformação.

As violações aos Direitos Humanos que constituem o conjunto de condições necessária ao desenvolvimento humano, acaba por coloca-los em evidência, paradoxalmente reforçando a sua importância. Contudo, as condições necessárias ao desenvolvimento humano a partir de novas perspectivas podem significar uma ótima oportunidade para gerar inovações buscando produzir fissuras na Dogmática Jurídica, predominantemente fechada (DE GIORGI, 2017, p. 328), que impossibilita maiores conexões com o ambiente complexo.

O desafio de compreender as conexões que constituem a rede de condições necessárias ao desenvolvimento humano na sociedade complexa, marcada pela Cibercultura, não permite que se utilize racionalidades lineares e muito menos lógicas binárias simplistas 
que acabam em dualismos ingênuos. Enfrentar os obstáculos desse contexto exige posturas diferentes, para se obter resultados ainda não alcançados.

Para que se possa pensar em mudanças significativas a partir do Direito é preciso considerar que esse não é capaz de determina-las, mas sim de estimulá-las. É preciso considerar que uma mudança significativa deva ser desencadeada de forma sistêmica. Para tanto é preciso ressignificar a importância da mudança no Direito, sem desconsiderar também a relevância da noção de estabilidade.

Uma forma de fazer isso pode ser através da concepção de Resiliência do Direito. A partir de um Direito Resiliente se pressupõe uma observação complexa dos obstáculos que possam existir em relação à proteção, garantia e realização dos Direitos Humanos.

Resiliência do Direito é a capacidade de observar a necessidade de promover mudança no Direito para alcançar um resultado desejado, identificar os respectivos obstáculos e ser capaz de promover inovação, gerando uma melhoria nas respostas jurídicas até então apresentadas, bem como, no próprio Direito, e com isso, voltando a reestabilizar o que até recentemente eram conflitos ou questões não solucionadas.

Assim, na perspectiva da Resiliência do Direito é possível assimilar mudanças pretendidas com o desenvolvimento humano, acentuando a importância de um conjunto complexo $^{13}$ de direitos já consagrados, mas destacando a sua convergência, por exemplo, entre Constituição da República Federativa do Brasil de 1988 e a Declaração Universal dos Direitos Humanos e as legislações infraconstitucionais, o que daria mais peso de importância para analisar o Direito em qualquer um dos seus ramos, a fim de acentuar a valorização e garantias ao desenvolvimento humano.

Assim, a partir de uma epistemologia complexa ${ }^{14}$ (ROCHA, 2013, p. 147) torna-se possível observar a necessidade de mudanças para efetivação de direitos fundamentais cuja realização parece depender de uma busca que não se alcança, por sempre estar no futuro. É através de uma epistemologia voltada à complexidade que se pode produzir decisões diferentes, rompendo assim a resistência dos obstáculos epistemológicos da dogmática

\footnotetext{
${ }^{13}$ Esse conjunto complexo de direitos já consagrados corresponde aos Direitos que constituem as condições necessárias para o desenvolvimento humano e que em si são direitos humanos e fundamentais, como por exemplo, educação, saúde, moradia e uma renda adequada para se viver e ter acesso a outros direitos necessários a viver uma vida com dignidade.

${ }^{14}$ Como epistemologia da complexidade se compreende as epistemologias disponíveis que correspondem a um âmbito reflexivo denominado por Leonel Severo Rocha de matriz pragmático sistêmica.
} 
jurídica. Isso gera certa desestabilização ${ }^{15}$ no que diz respeito à dinâmica da programação condicional do Direito, mas pode ser contornando na medida em que o processo de tomada de decisões, possa contar com um suporte avançado de conhecimento transdisciplinar. Tratase de uma forma de obter diagnósticos aprofundados sobre a sociedade (FLORES; ROCHA, 2016, p. 216-217) e os motivos de eventuais ineficácias de decisões jurídico-políticas que deveriam contribuir ou promover a realização do desenvolvimento humano.

Para tanto, os espaços de observações reflexivas transdisciplinares (NICOLESCU, 2005, p. 57) são de grande importância para incrementar as estruturas internas do sistema do Direito. Consequentemente também podem possibilitar um potencial de inovação que possa resultar em respostas diferentes aos problemas de violações a direitos que constituem condições necessárias ao desenvolvimento humano na policontexturalidade ${ }^{16}$ social. (TEUBNER, 2005, p. 87).

O Direito tem maiores condições de ser Resiliente quando se consegue maximizar o desenvolvimento de conhecimento de ponta, através de pesquisas sociológicas e transdisciplinares, compartilhadas democraticamente para dar suporte aos processos de tomada de decisão jurídica. Isso indica a importância de novos espaços para uma maior aproximação entre Universidades e Tribunais, bem como, um maior desenvolvimento da carreira de pesquisador no âmbito jurídico. (FLORES, ROCHA, 2016-a).

Esse suporte de conhecimento em rede pode ser pensado para se obter um conhecimento suficientemente consistente ${ }^{17}$. Isso pode permitir a produção de uma confiança sistêmica, na medida em que todo o processo seja construído democraticamente, com conhecimento de ponta e com transparência. (LUHMANN, 1996, p. 86). Essa confiança é uma confiança institucional de que os processos funcionam e são confiáveis. Isso permitiria então ao Direito inovar de forma evolutiva, para ao final retornar para uma dinâmica de assumir uma operacionalização de reestabilização dos novos parâmetros estabelecidos (pelas decisões jurídicas inovadoras) a fim de dar manutenção à ordem social. (LUHMANN, 1996, p. 87-88).

\footnotetext{
${ }^{15}$ Convém mencionar que esta desestabilização não é algo destrutivo, como a concepção de desequilíbrio abusivo como menciona Mathias (2013, p. 314), ou correspondente a uma desestabilização gerada pela violação da ordem normativa, mas uma desestabilização que diz respeito a um momento de mudança das próprias estruturas jurídicas, que por sua vez irá necessitar uma nova reestabilização.

16 A concepção de policontexturalidade indica a existência de múltiplos contextos no ambiente social correspondentes ao ambiente de sistemas sociais diferentes, onde existe uma dinâmica de operacionalização da linguagem e comunicação próprias daquele contexto.

${ }^{1717}$ Nesse processo de compreender as peculiaridades dos problemas sociais na atualidade, a pesquisa empírica de caráter sociológico, como parte de uma operacionalização resiliente do Direito, ganha especial importância.
} 
Numa perspectiva complexa, o desenvolvimento humano é muito mais complexo do que a mensuração estabelecida através dos indicadores estatísticos como temos hoje. Sem desconsiderar a importância dos diversos indicadores ${ }^{18}$ (MARIANO, 2019, p. XXI), é preciso reforçar a importância de se buscar permanentemente o aprimoramento dos processos a fim de obter respostas consistentes sobre as insuficiências em termos de efetividade das condições necessárias ao desenvolvimento humano e o que se poderia fazer para a superação dos problemas que ainda persistem.

Os Direitos Humanos permitem a observação de uma necessária dinâmica de repetição inerente ao Direito. São direitos que precisam ser repetidos, valendo-se da importância da programação condicional (do Direito) que acentua certa conservação de um passado de conquistas de Direitos elementares aos seres humanos. (LUHMANN, 1985, p. 27-28). Contudo, não se pode desconsiderar também a importância da programação ${ }^{19}$ finalística, que ao contrário abre a atenção do Direito para o futuro, para o diferente e para a inovação. (ROCHA, 2003, p. 196).

Nesse sentido, o desenvolvimento humano, com um conjunto complexos de condições fundamentais à sua realização permitem observar a importância da Resiliência para equacionar a produção de repetição (estabilização) e diferença (mudança) na operacionalização jurídica, a fim de promover uma atualização resiliente do Direito como um todo. Isso porque uma decisão que acentue alguma mudança, precisa encontrar uma motivação e fundamentação consistente. Essa equação resiliente de conservação e mudança nas operações do Direito, revela o caráter reflexivo na epistemologia jurídica, que operacionaliza o paradoxo de um Direito que é fechado e aberto simultaneamente, (TEUBNER, 1989). Assim o Direito Resiliente busca encontrar novas perspectivas de observar e acentuar as conexões entre condições de realização do desenvolvimento humano nas situações mais elementares, que convergem com a multidimensionalidade dos direitos fundamentais (MOREIRA, 2016, p. 1508) nas relações sociais que estejam à disposição da análise jurídica.

\footnotetext{
${ }^{18}$ Entre outros se pode citar o Índice de Desenvolvimento Social (IDS), o Índice de Progresso Genuíno (IPG), Índice de Desenvolvimento Humano Ajustado à Desigualdade (IDHAD), o Índice de Desenvolvimento Humano por Gênero (IDevG), o Índice de Desigualdade de Gênero (IDG) e o Índice de Pobreza Multidimensional (IPM).

${ }^{19}$ Neste sentido, Rocha traz a tona a pertinente observação sobre o processo de tomada de decisão, que em relação ao tempo pode ser de duas maneiras. Uma decisão pode ser tomada de acordo com uma programação condicional, entendendo assim, uma decisão voltada ao passado, que nega a produção de tempo, enfatizando a repetição. Ou de outra forma, uma decisão pode ser tomada segundo uma programação finalista, produzindo tempo que por sua vez, significa a produção de diferença. (ROCHA, 2003, p. 196).
} 
Por isso um Direito Resiliente de caráter Reflexivo permite desenvolver a disposição e capacidade de pensar o que normalmente e tradicionalmente não foi pensado (complexidade social). É um Direito com certa disposição para se operacionalizar diante da imprevisibilidade e incerteza. Para tanto, também busca o constante aprimoramento de suas estruturas internas. Isso resultará em ganhos evolutivos que no futuro permitirá ao sistema do Direito melhores condições de se abrir para o novo de forma consistente e confiável. (FLORES, ROCHA, 2016, p. 96).

Nesse sentido, a Resiliência do Direito (epistemológica, organizacional e comunicacional) permite melhores condições para enfrentar os desafios da realização do desenvolvimento humano diante da complexidade social contemporânea. Assim, a Resiliência do Direito, significa uma potencialidade fundamental para a realização do desenvolvimento humano, porque busca:

1) Epistemologicamente uma forma de observação e reflexão jurídica da complexidade contemporânea. Isso pressupõe uma disposição fundamental de considerar a complexidade social de fundamental importâncias para identificar e superar os obstáculos epistemológicos (internos). Isso parte do processo de superação das limitações da dogmática jurídica que ao produzir certo nível de ineficácia, estende esse efeito à realização dos direitos que são condições para a realização do desenvolvimento humano, relacionados às dimensões mais elementares do universo jurídico e social.

2) Operacionalmente busca otimizar e aprimorar resilientemente o potencial das organizações, tanto para gerenciar uma grande quantidade de informações relevantes, como para criar espaços transdisciplinares, através dos quais, os conhecimentos de ponta desenvolvidos por universidades possam ser democraticamente compartilhados à disposição do Judiciário, a fim de servir de alternativas de solução, dando suporte aos processos de tomada de decisões jurídicas em prol da realização do desenvolvimento humano.

3) Comunicacionalmente busca fazer com que todo o processo jurídico seja reflexivo, procurando aprimorar tanto as operações internas como a capacidade de alcançar eficácia nas suas comunicações com o ambiente social. Assim, potencializa-se as possibilidades de o Direito produzir um resultado mais eficaz na sociedade e consequentemente respostas mais satisfatórias à realização do desenvolvimento humano na atualidade.

Isso tudo pressupõe condições epistemológicas e operacionais para pensar a inovação do Direito. Mais do que desenvolver conhecimentos teóricos sobre os Direitos Humanos, assinar tratados e publicar legislações, é preciso que o desenvolvimento humano aconteça 
efetivamente na atualidade como condição fundamental de realização e afirmação dos Direitos Humanos e forma ampla.

Para tanto é preciso que o Sistema do Direito possua uma estratégia de observação através de pesquisas empíricas construtivistas, a fim de diagnosticar os obstáculos existentes no contexto atual que dificultam a plena realização do Direito, bem como, os pontos a serem enfrentados de forma sistêmica na sociedade. Isso é possível nas perspectivas de um Direito Resiliente, que permite a observação do conjunto complexo de condições para o desenvolvimento humano como um novo espaço interpretativo, através dos quais se pode vislumbrar alternativas diferentes ainda não suficientemente experimentadas. (DE GIORGI, 2017, p. 329).

\section{CONSIDERAÇÕES FINAIS}

A sociedade atual caracteriza-se por um ambiente altamente complexo. Essa complexidade é potencializada pela expansão das tecnologias, em especial pelas tecnologias digitais. As tecnologias digitais de informação e comunicação permitem uma grande transformação nas relações sociais, possibilitando novos espaços de interações através do ciberespaço, repleto de imprevisibilidades, novidades e incertezas. Nesse novo contexto onde as relações ganham dimensões virtuais, surge também um conjunto de tendências que condicionam as formas de pensar, agir e de se comportar na sociedade, que Pierre Levy denominou de Cibercultura.

Assim a Cibercultura vem reconfigurando e transformando as relações sociais, desencadeando múltiplas mudanças e criando um cenário difícil, mas também muito fértil para compreender a complexidade social contemporânea. A Cibercultura, bem como as tecnologias digitais não significam necessariamente aspectos positivos ou negativos para o desenvolvimento humano e social. Mas paradoxalmente podem possibilitar as duas manifestações. Possui tanto um potencial para a emancipação como para a alienação.

Isso afeta diretamente as condições para o desenvolvimento humano. Trata-se de uma categoria que emerge no âmbito das iniciativas promovidas pelo PNUD, com intuito de iniciar um movimento de mudança, indicando que todos os desenvolvimentos, em especial o econômico, deve ter correspondência com o desenvolvimento humano. Apesar dos avanços e criação de diversos indicadores para mensurar o nível de desenvolvimento humano, entre os quais o mais importante é o IDH, a concepção de desenvolvimento humano 
possui um potencial eminentemente sistêmico. Possui um potencial de complexidade que está para além das possibilidades de medição e se coloca como um desafio a ser enfrentada para continuar o seu aprimoramento.

De forma ampla, o desenvolvimento humano pressupõe a formação de um cidadão capaz de se determinar com autonomia, podendo escolher a forma de vida que pretende viver, considerando que terá as condições necessárias para tal e só não conseguirá se optar por não fazer o que é necessário e está ao alcance de todos que tenham a mesma intenção.

Isso sugere ambivalência para o desenvolvimento humano, com um potencial tanto de emancipação como de alienação. Assim, as tecnologias acabam por produzir uma inclusão obrigatória de todos, pois gera uma grande dependência tecnológica. Na medida em que não ocorra certa adesão ou adaptação, corre-se um grande risco de ser excluído das comunicações, que na cibercultura significa uma violenta exclusão social, extremamente agressiva para a realização do desenvolvimento humano na sociedade complexa.

Outro problema que pode ser evidenciado com a Cibercultura é que a sua dinâmica traz inovações sociais que problematizam profundamente a epistemologia jurídica de caráter mais tradicional. Assim a complexidade da sociedade que é potencializada pelo desenvolvimento da Cibercultura, coloca em evidência as fragilidades da dogmática jurídica que podem ser observadas, basicamente de duas maneiras:

1) Através de uma epistemologia reducionista e conservadora que sacrifica a complexidade em prol de certa operacionalização excessivamente simplificada.

2) Através de uma simplificação manipulada racionalmente como parte de uma estratégia formal para dar manutenção a certo controle na produção de sentido jurídico (em decisões jurídicas).

Essas duas formas constituem um tipo de postura jurídica que parece transportar certo conformismo e comodismo com uma produção jurídica dogmática, voltada a afastar qualquer crítica que coloque em risco a manipulável estabilidade da dogmática jurídica. Considerando a sua armadura dogmática do Direito que cria uma proteção contra críticas relevantes, se garante, em nome de certa operacionalização, a manutenção de uma visão de mundo mais simples do que ele de fato se apresenta. ${ }^{20}$ Isso dificulta a compreensão das condições necessárias para o desenvolvimento humano que precisam ser compreendidas numa perspectiva sistêmica e num contexto complexo.

\footnotetext{
${ }^{20}$ Isso indica certa conservação de uma racionalidade moderna, que pressupõe uma observação excessivamente conservadora, impedindo o acesso pleno à complexidade.
} 
Para enfrentar os desafios da Cibercultura e da sociedade complexa é preciso um requestionamento, uma revisão da epistemologia jurídica, como forma de aprimorar a capacidade de observação no Direito. Nesse sentido, desenvolver a Resiliência do Direito parece uma perspectiva apropriada, como uma alternativa de observação que pressupõe novas perspectivas epistemológicas voltadas à complexidade, ao permanente requestionamento, aprendizado e inovação.

Assim, convém mencionar que a Resiliência do Direito é a capacidade de observar a necessidade de promover mudança para enfrentar um desafio juntamente com a capacidade e o propósito de efetivar mudanças, experimentando uma desestabilização que é necessária para a evolução, apresentando novas e melhores soluções e retornando a se reestabilizar de forma aperfeiçoada, a fim de conservar e aprimorar a manutenção da ordem jurídica.

A partir dessa dinâmica pode-se vislumbrar novas observações por parte do Direito que podem ressignificar a importância da convergência das normas de direitos humanos, das normas constitucionais de direitos fundamentais e das legislações infraconstitucionais para acentuar o desenvolvimento humano. Assim, essa observação, necessariamente convergente, ganha maior peso ao ser relacionada com as condições fundamentais ao desenvolvimento humano, acentuando a sua importância nas relações mais elementares na dinâmica social.

Nesse sentido, a contribuição da Resiliência do Direito pode ser no sentido de que ao propor novas formas de observação pode reforçar a importância de compreender a complexidade do desenvolvimento humano e assim acentuar o seu caráter sistêmico. Da mesma forma que uma exclusão em um dado sistema pode implicar em outras exclusões sistêmicas o mesmo ocorre com a inclusão, sobretudo com aqueles direitos que são condições para o desenvolvimento humano. Esse novo olhar do desenvolvimento humano numa perspectiva sistêmica e resiliente pode possibilitar novos espaços interpretativos, o que por sua vez pode oportunizar decisões diferenciadas em razão de se buscar observar em todas as áreas do Direito, como, por exemplo, de direito civil, direito penal ou direito tributário, a sua relação convergente com aspectos de Direitos Humanos, Direitos Fundamentais e os Direitos ao Desenvolvimento Humano. Essas decisões diferentes podem ser observadas a partir de um espaço de construção compartilhada de conhecimento, oriundo de pesquisas de ponta que podem servir aos tribunais na implementação de processos de tomada de decisão jurídica. Decisões que podem inovar tentando recuperar um empenho maior na realização de Direitos Humano, Direitos Fundamentais e Desenvolvimento Humano, que ainda não foram suficientemente implementados pragmaticamente. Isso seria possível de forma 
inovadora e confiável a partir de um suporte de conhecimentos avançados e um processo de construção da tomada de decisão, de certa forma, com suporte transdisciplinar, em um espaço democrático e através de processos transparentes.

Com esse processo o Direito deve permitir a observação de suas próprias insuficiências e a necessidade de mudar para obter melhores resultados. Assim ele saí de uma perspectiva dogmática, enfrenta os desafios e dificuldades da mudança, mesmo assim é capaz de promover uma mudança evolutiva e de produzir um resultado diferente dos até então apresentados. Na sequência, buscando uma resiliência comunicativa para que tenha uma repercussão eficaz do que foi decidido no contexto da sociedade. Esse processo sempre pressupõe certa aquisição evolutiva, ou seja, uma melhoria nas estruturas do Direito que será fundamental para retornar à operacionalização de reestabilizar as novas situações, afim de dar manutenção à ordem jurídica (dinamicamente) estável.

Neste processo além da ressignificação sistêmica do desenvolvimento humano, também se busca operacionalizar o aprimoramento epistemológico, operacional e comunicacional do Direito. É só buscando uma epistemologia jurídica, uma operacionalização e uma comunicação mais resiliente do Direito em geral, que se poderá buscar evidenciar a relação dos Direitos Humanos em todas as pontas das relações jurídicas. Assim se poderá buscar garantir a efetividade das formas de direitos mais elementares, mas agora com o selo dos Direitos Humanos, dos Direitos fundamentais e do Direito ao Desenvolvimento Humano, colado nas decisões que busquem sua necessária realização na sociedade.

Para que se possa melhor compreender esse processo que também objetiva o aprimoramento do Direito para que ele seja capaz de apresentar respostas mais satisfatórias aos problemas sociais, é preciso que o Direito: a) consiga desenvolver uma observação que contemple em seu horizonte o máximo possível de aspectos da complexidade social; b) consiga romper com seus próprios obstáculos epistemológicos internos, no sentido de ser capaz de transgredir sua própria armadura dogmática, a fim de tentar alternativas de solução que ainda não foram tentadas; c) busque certa sofisticação que lhe permita acentuar a programação finalística (diferença) de forma a desencadear um aprendizado no próprio sistema jurídico; d) retome sua estabilização de forma aprimorada, acentuando a importância de pensar simultaneamente à elaboração de suas decisões aos problemas sociais e também o próprio processo evolutivo do Direito. 
A Resiliência do Direito significa uma nova perspectiva de observação e ao mesmo tempo, um potencial de produção de diferença, aprendizado e inovação do Direito, a fim de se ter mais eficácia e produzir respostas mais satisfatórias às demandas sociais, mostrandose resiliente diante dos desafios das transformações da sociedade contemporânea. É essa disposição para produzir diferença que é necessária para pensar e buscar a realização do desenvolvimento humano na sociedade atual.

Contudo, não se trata de sustentar simplesmente que o Direito deve ser flexível e se abrir para o novo, ou que deva mudar de qualquer forma pois está numa sociedade que muda constantemente. Ser Resiliente não significa apenas ser flexível, é mais do que isso. ${ }^{21} \mathrm{Um}$ Direito Resiliente pressupõe conservar o que já foi conquistado no passado, (Direitos Humanos), produzindo repetição, sem incorrer em um excessivo conservadorismo. Produz mudança (diferença) abrindo a possibilidade para perspectivas inovadoras, sem incorrer, contudo, em elaborações levianas e irresponsáveis. O que garante manter e não exceder certos limites são processos construtivos de reflexões dialógicas, transparentes e democráticas, pautadas por "conhecimentos de ponta". ${ }^{22}$ Assim, um Direito Resiliente além de buscar identificar e superar obstáculos, tanto internos como externos, também busca o seu aprimoramento com esse processo, afim de observar o desenvolvimento humano em uma perspectiva sistêmica, o que pode permitir a observação de novos espaços interpretativos no contexto da Cibercultura, através dos quais se pode vislumbrar alternativas diferentes, ainda não suficientemente exploradas pela perspectiva dogmática do Direito.

\section{REFERÊNCIAS}

BACHELARD, Gaston. La formation de l'esprit scientifique: contribuition a une psycaalyse de la connaissance. Paris: Librairie Philosophique J. Vrin, 2011.

CASTELLS, Manuel, A sociedade em rede. Tradução de Roneide Venancio Majer. 8 ed. São Paulo: Paz e Terra, 2005.

CLAM, Jean. Questões fundamentais de uma teoria da sociedade: contingência, paradoxo, só-efetuação. São Leopoldo: Editora Unisinos, 2006.

\footnotetext{
${ }^{21}$ A flexibilidade pode ser importante se articulada de forma resiliente e construtiva, mas por outro lado, também pode servir para manipulações através de mudanças irresponsáveis.

${ }^{22}$ A concepção de "conhecimento de ponta" significa os conhecimentos mais evoluídos tanto do ponto de vista teórico, como em relação aos processos e procedimentos de sua implementação, considerando uma perspectiva inter e transdisciplinar. Significa buscar compartilhar o desenvolvimento do conhecimento com a multiplicidade de áreas de saber e suas respectivas pesquisas que também possa servir socialmente de forma transdisciplinar.
} 
CORSI, Giancarlo; BARALDI, Cláudio; ESPÓSITO, Elena. Glosario sobre la teoria social de Niklas Luhmann. Tradução de Miguel Romero Pérez y Carlos Villalobos. Universidad Iberoamericana. Guadalajara, México: Diseño y Letras, S.A, 1996.

DE GIORGI, Raffaele. Por uma Ecologia dos Direitos Humanos. In: Revista Opinião Jurídica. Fortaleza, ano 15, no 20, p. 324-340, jan/jun. 2017. Disponível em:< http://periodicos.unichristus.edu.br/index.php/opiniaojuridica/article/view/1506/468>. Acessado em: 24 de jun. 2018.

FERRAZ JR, Tercio Sampaio. Introdução ao Estudo do Direito: técnica, decisão, dominação. São Paulo: Atlas, 2011.

FLORES, Luís Gustavo Gomes; ROCHA, Leonel Severo. Resiliência do Direito. Curitiba: Prismas, 2016.

Resiliência do Direito: a inovação jurídica, entre universidades e tribunais. 13 v. Revista de Direito Público - Revista Oficial do Programa de Mestrado em Direito Constitucional da Escola de Direito de Brasília. Brasília: Instituto Brasiliense de Direito Público. 2016-a. Disponível em:

<https://www.portaldeperiodicos.idp.edu.br/direitopublico/article/view/2765>. Acessado em: 2, mar, 2020.

FLORES, Luís Gustavo Gomes. OBSTÁCULOS EPISTEMOLÓGICOS DE BACHELARD E CONSTRUTIVISMO SISTÊMICO: REQUESTIONAMENTOS AOS DIREITOS HUMANOS. In: Revista Brasileira de Filosofia do Direito. v. 4, n. 2 Porto Alegre: CONPEDI, jul/dez. 2018, p. 128 - 147. Disponível em: <https://indexlaw.org/index.php/filosofiadireito/article/view/4928/pdf>. Acessado em 3, jun. 2020.

FOERSTER, Heinz von. Visão e Conhecimento: Disfunções de segunda ordem. In: Novos Paradigmas, Cultura e Subjetividade. Organizado por Dora Fried Schnitmann; Tradução de Jussara Haubert Rodrigues, Porto Alegre: Artes Médicas, 1996.

IELBO, Marcus Lobo de Souza; KETSCHAMNN, Ângela. A universalidade dos direitos humanos no discurso internacional: o debate continua. In: ROCHA, Leonel Severo;

STRECK, Lênio Luiz. Anuário do Programa de Pós-Graduação em Direito, Mestrado e Doutorado. São Leopoldo: Unidade Ciências Jurídicas, 2003-a.

JANELA DA ALMA. Direção: João Jardim, Walter Carvalho; Produtor: João Jardim, Produtoras: Ravina Films; Dueto Films; 22, out. 2001, DVD (73min.).

LEVY, Pierre. Cibercultura. Tradução de Carlos Irineu da Costa. 2 ed. São Paulo: Ed. 34, 2007.

LUHMANN, Niklas. La sociedad de la sociedad. México: Herder, 2007.

Sistemas Sociais: Esboço de uma teoria gera. Petrópolis: Vozes, 2016. 
Confianza. Barcelona/España: Anthropos; México: Universidad Iberoamericana; Santiago de Chile: Instituto de Sociología. Pontificia Universidad Católica de Chile, 1996.

. Sociologia do Direito I. Tradução de Gustavo Bayer. Rio de Janeiro: Tempo Brasileiro, 1983.

Sociologia do Direito II. Tradução de Gustavo Bayer. Rio de Janeiro: Tempo Brasileiro, 1985.

MATHIAS, Guilherme Valdetaro. $O$ abuso do direito. In: Revista Quaestio Iuris, v. 6, n 1, 2013, p. 314-375. Disponível em:< https://www.e-

publicacoes.uerj.br/index.php/quaestioiuris/article/view/9590/7424>. Acessado em 3, abr. 2020.

MATURANA, Humberto R; VARELA, Francisco J. A árvore do conhecimento: as bases biológicas da compreensão humana. São Paulo: Palas Athena, 2001.

MOREIRA, Adilson José. Direitos Fundamentais como estratégias antihegemônicas: um estudo sobre a multidimensionalidade de opressões. In: Revista Quaestio Iuris, v. 9, n 3, 2016, p. 314-375. Disponível em:< https://www.e-

publicacoes.uerj.br/index.php/quaestioiuris/article/view/9590/7424>. Acessado em 5, fev. 2020 .

NICOLESCU, Basarab. O Manifesto da Transdisciplinaridade. São Paulo: Triom, 2005.

PISCHETOLO, Magda. Inclusão digital e educação: a nova cultura da sala de aula. Rio de Janeiro: Editora PUC-Rio, 2016.

PNUD - Programa das Nações Unidas para o Desenvolvimento. Desenvolvimento

Humano e IDH. s/d. Disponível

em: $<$ https://www.br.undp.org/content/brazil/pt/home/idh0.html $>$. Acessado em: 02, jan. de 2020 .

PNUD - Programa das Nações Unidas para o Desenvolvimento. Entender la desigualdade de las capacidades. In: Informe sobre Desarrollo Humano 2019 - Más allá del ingreso, más allá de los promedios, más allá del presente: Desigualdades del desarrollo humano en el siglo XXI. Nova York/Estados Unidos: AGS, 2019.

<http://hdr.undp.org/sites/default/files/hdr_2019_overview_-_spanish.pdf >. Acessado em: 07, jan. de 2020.

ROCHA, Leonel Severo. Epistemologia Jurídica e Democracia. 2 ed. São Leopoldo: Ed. UNISINOS, 2003.

A construção do tempo pelo direito. In: ; STRECK, Lênio Luiz. Anuário do

Programa de Pós-Graduação em Direito, Mestrado e Doutorado. São Leopoldo: Unidade Ciências Jurídicas, 2003-a.

Epistemologia do Direito: revisitando as três matrizes jurídicas. In: Revista de Estudos Constitucionais, Hermenêutica e Teoria do Direito (RECHTD). v. 5, n. 2, jul-dez, 
2013, p. 141-149. Disponível

em: <http://revistas.unisinos.br/index.php/RECHTD/article/view/rechtd.2013.52.06/3934>. Acessado em: 14, fev. 2020.

TAVARES, José. A resiliência na sociedade emergente. In TAVARES, José (Org.). Resiliência e educação. São Paulo: Cortez, 2001.

Trabalho recebido em 23 de março de 2019

Aceito em 04 de dezembro de 2020 